\title{
A simulation study of physiological factors affecting pharmacokinetic behaviour of organic solvent
}

\section{vapours}

\author{
A Sato, K Endoh, T Kaneko, G Johanson
}

\begin{abstract}
At a given external dose of an inhaled chemical the internal dose or the amount absorbed into the body varies depending on pulmonary ventilation and other physiological factors. Such variability is of concern in the development of biological indices of occupational exposure to organic solvent vapours. This paper discusses how physiological factors may influence the pharmacokinetic behaviour of inhaled organic solvent vapours, especially in relation to monitoring of biological exposure. To illustrate the discussion a computer based physiological pharmacokinetic model was used describing quantitatively the influence of body size, body fat content, and sex on the pharmacokinetic behaviour of trichloroethylene. Absorption, distribution, metabolism and excretion of trichloroethylene were found to vary according to the different anatomical features of men and women. Body build (body weight and body fat content) also affected the pharmacokinetic behaviour of this solvent.
\end{abstract}

The dose of inhaled chemicals (exposure level or external dose) is the product of exposure concentration and exposure duration. Time weighted average concentration (TWA) is a representative index of the external dose. When the external exposure expressed by concentration $\times$ duration is the same for different workers, the amount that effectively enters the alveoli may differ, depending on their pulmonary ventilation; pulmonary ventilation varies with sex,

Department of Environmental Health, Medical University of Yamanashi, Tamaho, Yamanashi, 409-38 Japan

A Sato, K Endoh, T Kaneko

Division of Work and Environmental Physiology,

National Institute of Occupational Health, S-171 84

Solna and the Department of Occupational

Medicine, University Hospital, S-751 85 Uppsala,

Sweden

G Johanson age, body build, and most prominently with energy expenditure.

Biological monitoring of exposure is a measure of the amount of chemical absorbed into the body and is performed by measuring the concentration of chemical or its metabolites in biological samples. Any physiological factor which influences the absorption, distribution, metabolism, or elimination of a chemical can affect the result of exposure monitoring. A physiological pharmacokinetic model is a useful tool to obtain an insight into these effects, as each compartment employed in the model represents a particular tissue or organ group of anatomical significance. The impact of body size and physical activity on the pharmacokinetic behaviour of organic solvents has been studied with this type of model. ${ }^{12}$ The aim of our paper is to discuss and show how two factors-namely, body build (body weight and body fat content) and sex-may affect biological monitoring of exposure to organic solvents. A physiological simulation model for trichloroethylene provides an example.

\section{Methods}

Our simulation model was composed of seven compartments: the lung compartment, vessel rich tissue compartment, vessel poor tissue compartment, muscle compartment, fat tissue compartment, gastrointestinal compartment, and hepatic compartment. ${ }^{3}$ To describe the transfer of trichloroethylene in the system, an equilibrium was assumed always to exist between the concentration in a compartment and the concentration in the blood leaving the compartment. The loss of trichloroethylene by metabolism was assumed to occur only in the hepatic compartment and follow Michaelis-Menten type kinetics. Thus the rate of metabolism was expressed by the formula $V \max \cdot \mathrm{CH} /(\mathrm{Km}+\mathrm{CH})$, where $V \max$ is the maximum velocity, $\mathrm{Km}$ the Michaelis constant, and $\mathrm{CH}$ the concentration of trichloroethylene in the hepatic compartment. It was also assumed that trichloroethylene is first metabolised to chloral hydrate, which is then converted to trichloroacetic acid (TCA) and trichloroethanol (TCE). A fraction of TCA is formed from TCE. The TCA and TCE are 
excreted in the urine either directly or after conjugation. For the transfer of trichloroethylene metabolites, the whole body was treated as a single compartment and first order kinetics were assumed for the sake of simplicity. ${ }^{4}$ A mass balance of trichloroethylene was performed on each compartment and its transfer throughout the system was expressed in the form of simultaneous differential equations that were then solved numerically with a personal computer. ${ }^{35}$

The table shows the parameters used in the simulation. The basic assumptions were that the volume of an organ or tissue is related to body weight $(\mathrm{Bw}(\mathrm{kg}))$ and the energy related parameters such as blood flow and metabolism are a function of body surface area and therefore they are proportional to some power function of body weight. The power of 0.7 with the constant of 0.296 (cardiac output in $1 / \mathrm{min}$ $\left.=\mathrm{Q}_{\mathrm{C}}=0.296(\mathrm{Bw})^{0.7}\right)$ was used to calculate cardiac output at rest. Alveolar ventilation was assumed to be equal to cardiac output. ${ }^{6}$ The metabolic constants of trichloroethylene (Vmax $3.2 \mathrm{mg} / \mathrm{min} ; \mathrm{Km} 2.5 \mathrm{mg} / \mathrm{l}$ ) reported by Koizumi ${ }^{7}$ were adapted in our study. It was assumed that Vmax is described by $0.17(\mathrm{Bw})^{0.7}$ and $\mathrm{Km}$ is independent of body size. The formula $3.08 \times 10^{-5}(\mathrm{Bw})^{0.82}$ reported by Adolph ${ }^{8}$ was used to calculate urinary output in $1 / \mathrm{min}$.

A study ${ }^{3}$ with the present model showed good agreement between simulated time curves of blood concentration and urinary metabolite excretion and experimentally observed curves in male volunteers exposed to $100 \mathrm{ppm}$ trichloroethylene for four hours. 9

\section{Results and discussion BODY BUILD \\ Body size}

To study the effece of body size on the pharmacokinetic behaviour of trichloroethylene, a scale up or scale down of body size was made without changing the body framework (table). Men of various sizes (40$100 \mathrm{~kg}$ ) were exposed to $50 \mathrm{ppm}$ trichloroethylene for eight hours (8:00-12:00 and 13:00-17:00 hours), and the concentration of trichloroethylene in the blood and the excretion rate of urinary metabolites (TCA and TCE) were computed over time during and after the exposure.

Because alveolar ventilation depends on body weight, absorption into the body increased with increased body weight. Increased uptake was not reflected, however, by a similar increase in the blood concentration of the solvent because it was diluted in a larger volume (fig 1A). On the other hand, the amounts of metabolites TCA and TCE excreted in urine increased with body size (fig 1B). This is not surprising because liver size increases proportionately with body weight and metabolic capacity (Vmax) increases with a power function of body weight. The urinary concentration of metabolites

Simulation parameters for man

\begin{tabular}{|c|c|c|c|c|c|}
\hline \multirow[b]{2}{*}{ Compartment } & \multicolumn{2}{|c|}{ Volume $(l)^{\star}$} & \multicolumn{2}{|c|}{ Blood flow $(l / \mathrm{min})^{\star}$} & \multirow{2}{*}{$\frac{\text { Partition coefficient } \dagger}{\text { Men and women }}$} \\
\hline & Men & Women & Men & Women & \\
\hline $\begin{array}{l}\text { Lung (LC) } \\
\text { Vessel rich (VRC) } \\
\text { Vessel poor (VPC) } \\
\text { Muscle (MC) } \\
\text { Fat (FC) } \\
\text { Gastrointestinal (GC) } \\
\text { Hepatic (HC) } \\
\text { Arteriovenous shunt }\end{array}$ & $\begin{array}{l}\mathrm{V}_{\mathrm{L}} \pm \\
0.030 \mathrm{Bw} \\
0.085 \mathrm{Bw} \\
0.415 \mathrm{Bw} \\
0.211 \mathrm{Bw} \\
0.019 \mathrm{Bw} \\
0.023 \mathrm{Bw} \\
-\end{array}$ & $\begin{array}{l}\mathrm{V}_{\mathrm{L}} \\
0.030 \mathrm{Bw} \\
0.085 \mathrm{Bw} \\
0.315 \mathrm{Bw} \\
0.365 \mathrm{Bw} \\
0.019 \mathrm{Bw} \\
0.023 \mathrm{Bw} \\
-\end{array}$ & $\begin{array}{l}\mathrm{Q}_{c} \S \\
0.379 \mathrm{Q}_{\mathrm{c}} \\
0.063 \mathrm{Q}_{\mathrm{c}} \\
0.114 \mathrm{Q}_{\mathrm{c}} \\
0.053 \mathrm{Q}_{\mathrm{c}} \\
0.171 \mathrm{Q}_{\mathrm{c}} \\
0.069 \mathrm{Q}_{\mathrm{c}} \\
0.151 \mathrm{Q}_{\mathrm{c}}\end{array}$ & $\begin{array}{l}\mathrm{Q}_{\mathrm{C}} \\
0.379 \mathrm{Q}_{\mathrm{C}} \\
0.063 \mathrm{Q}_{\mathrm{C}} \\
0.087 \mathrm{Q}_{\mathrm{C}} \\
0.092 \mathrm{Q}_{\mathrm{C}} \\
0.171 \mathrm{Q}_{\mathrm{C}} \\
0.069 \mathrm{Q}_{\mathrm{C}} \\
0.139 \mathrm{Q}_{\mathrm{C}}\end{array}$ & $\begin{array}{l}-3 \cdot 42 \\
1 \cdot 64 \\
1 \cdot 64 \\
68 \cdot 0 \\
2 \cdot 79 \\
4 \cdot 40 \\
-\end{array}$ \\
\hline \multicolumn{2}{|l|}{ Parameters } & Men & \multicolumn{2}{|c|}{ Women } & Men and women \\
\hline \multicolumn{2}{|c|}{$\begin{array}{l}\text { Blood/air partition coefficient }(i) \\
\text { Lung/air partition coefficient } \\
\text { Vmax }(\mathrm{mg} / \mathrm{min}) \\
\mathrm{Km}(\mathrm{mg} / \mathrm{l}) \\
Q_{\mathrm{L}+\ddagger}\end{array}$} & $\begin{array}{l}0.296(\mathrm{Bu} \\
3.08 \times 1\end{array}$ & ${ }^{2} \pi$ & 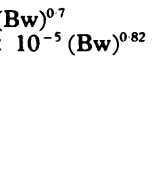 & $\begin{array}{l}9 \cdot 92^{\star \star} \\
26 \cdot 6^{\star \star} \\
0 \cdot 17(\mathrm{Bw})^{0.7}+\dagger \\
2 \cdot 5+\dagger \\
\mathrm{Q}_{\mathrm{C}}\end{array}$ \\
\hline
\end{tabular}

*The values for men were adapted from Davis and Mapleson. ${ }^{10}$

†Calculated from the rat tissue/blood partition coefficients and human blood/air partition coefficient reported by Sato $e t$ al. ${ }^{9}$

$\mp \mathrm{V}_{\mathrm{L}}$ (volume of lung compartment) $=$ (tidal volume) $\times 1 / 3+$ (functional residual capacity) + (volume of lung tissue) $\times$ (lung/air partition coefficient) + (volume of arterial blood) $\times \lambda .^{11}$

$\S$ The value of $Q_{C}$ (cardiac output) for men, $0 \cdot 296(\mathrm{Bw})^{0.7}$, was chosen by assuming $\mathrm{Q}_{C}$ at rest of a standard man of $70 \mathrm{~kg}$ to be $5 \cdot 81 / \mathrm{min}$.

The $\mathrm{Q}_{\mathrm{C}}$ of women was set $10 \%$ less than that of men.

$\| \mathrm{Bw}=$ Body weight $(\mathrm{kg})$.

TFrom Adolph. ${ }^{8}$ Urine output of women was set $10 \%$ less than that of men.

$\star \star$ From Sato et al. ${ }^{9}$

†+From Koizumi.

$\ddagger \mathrm{Q}_{\mathrm{L}}$ = Alveolar ventilation $(\mathrm{l} / \mathrm{min})$. 

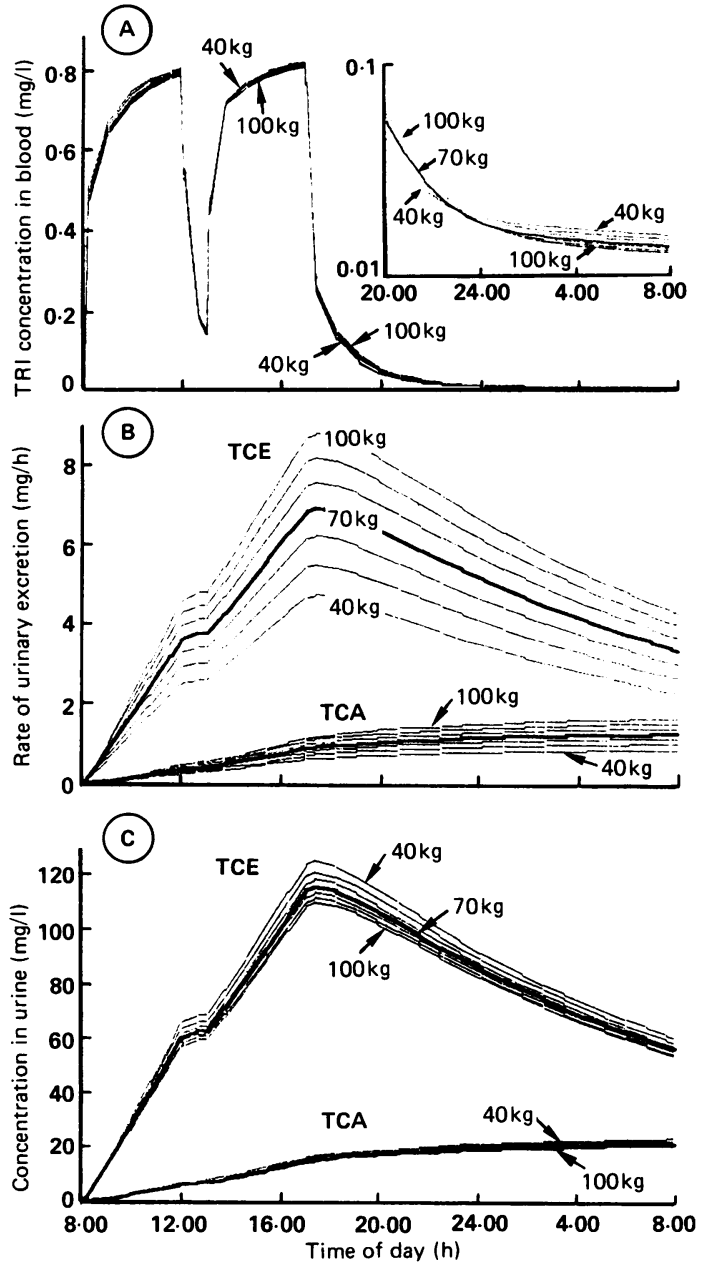

Figure 1 Simulated pharmacokinetic behaviour of TRI in relation to body size. Men with various body weights (40$100 \mathrm{~kg})$ were submitted to a $50 \mathrm{ppm} \times 8 \mathrm{~h}(8: 00-12: 00$ and 13:00-17:00 hours) exposure to TRI. The concentration of $T R I$ in blood is shown on both an arithmetic and a logarithmic scale (A) and the urinary excretion of TRI metabolites ( TCA; TCE) as excretion rate, $B$ and urinary concentration $\$.

was hardly affected by body weight because urinary flow also increases with body weight (fig 1C) and the power employed to relate urine output to body weight is higher $(0.82)$ than the power $(0.7)$ of alveolar ventilation or Vmax. This is the reason why, by contrast with the rate of urinary excretion, the highest metabolite concentration was found in the man with the smallest body size $(40 \mathrm{~kg})$.

The average body size is different among ethnic groups. Not only is the volume of each organ or tissue different but the alveolar ventilation, cardiac output, tissue blood flow, and urine output also differ between such groups. Our study indicates that data concerning biological exposure monitoring from workers in one country should be used with caution in other countries.

\section{Body fat content}

Three types of man were chosen-namely, a standard man (body weight $70 \mathrm{~kg}$ ) with $14 \cdot 81$ (corresponding to $0.211 \mathrm{Bw}$ ) of body fat, an obese man with $29.6 \mathrm{l}$, and a slim man with $7 \cdot 41$. Blood flow through the fat tissue was changed proportionately according to the tissue volume. All physiological parameters other than the volume and blood flow of fat tissue were assumed to be the same. These men were exposed to $50 \mathrm{ppm}$ trichloroethylene for eight hours (8:00-12:00 and 13:00-17:00 hours), and the concentration of trichloroethylene in the blood and the rate of metabolite excretion into the urine were computed over time during and after the exposure.

Trichloroethylene concentration in the blood during exposure was highest in the slim and lowest in the obese man (fig 2A). Similarly, the amount of urinary
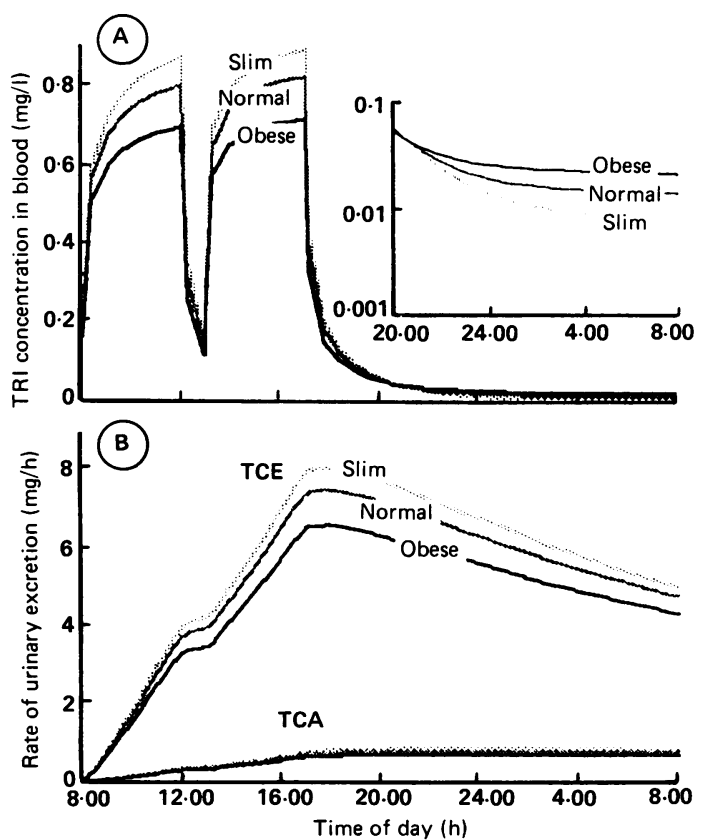

Figure 2 Effects of body fat content on concentration of $T R I$ in blood (A) and urinary excretion of TRI metabolites (TCA;TCE) (B). The simulations were performed for $a$ $50 \mathrm{ppm} \times 8 \mathrm{~h}(8: 00-12: 00$ and 13:00-17:00 hours) exposure to TRI. Standard, a normal man (body fat, $0 \cdot 211$ Bw or 14.8 l); slim, a slim man (body fat, 7.4 l); obese, an overweight man (body fat, 29.6 l). Concentration of TRI in the blood is shown both on an arithmetic and a logarithmic scale. 
metabolites excreted by the obese man was smaller than that excreted by the standard or slim man (fig 2B). As the fat-blood partition coefficient of trichloroethylene is very large (68), trichloroethylene is almost completely extracted from blood passing through fat tissues. Thus during exposure, fat tissue acts as an efficient scavenger of trichloroethylene. Accordingly, the amount of trichloroethylene available for metabolic transformation decreases with increasing obesity.

In due course after exposure the rate of trichloroethylene removal from fat tissue begins to rate limit the overall transfer of trichloroethylene. At this time the amount of trichloroethylene released from the fat tissue of the obese man is almost twice as large and that from the slim man half as large as that of the standard man. Consequently, three hours after exposure (20:00 hours) the blood concentration of trichloroethylene was reversed among the three subjects, and 16 hours after exposure the concentration in the obese man was about twice as high and in the slim man half as high as that of the standard man (fig 2A). The amounts of urinary metabolites were also reversed among the three subjects in the final stage.

The conclusion described above was drawn from a simulation study in which the blood flow through fat tissue was assumed to change in proportion to the volume of the tissue. As the rate of trichloroethylene transfer to and from fat tissue is determined by the volume of fat tissue and the blood flow through it, the result of such a simulation study is expected to be dependent on the relation between the volume of fat tissue and the blood flow used. This was confirmed by a simulation study where the volume of fat tissue was kept at a level of 29.61 (the same as that of the obese man described above) with three different blood flows through the tissue-namely, $0.31 \mathrm{l} / \mathrm{min}(1 / 2$ that of the obese man), $0.46 \mathrm{l} / \mathrm{min}(3 / 4$ that of the obese man), or $0.62 \mathrm{l} / \mathrm{min}$ (the same as that of the obese man) (fig 3). During exposure, the higher the blood flow, the lower the trichloroethylene concentration in blood, although the concentration was highest in the obese man with the highest blood flow about three hours after the end of exposure (fig 3A). In accordance with this, the higher the blood flow through fat tissue, the lower the rate of urinary metabolite excretion (fig 3B). The reason was mentioned earlier. In the long run, however, the rate in the obese man with the higher blood flow surpassed that in the man with the lower blood flow (data not shown).

\section{SEX}

Anatomical features of women are characterised by a slender frame, thin muscle, and ample body fat. The table shows the simulation parameters for female workers. The volume of the muscle compartment was assumed to follow the formula $0.315 \mathrm{Bw}$ and the
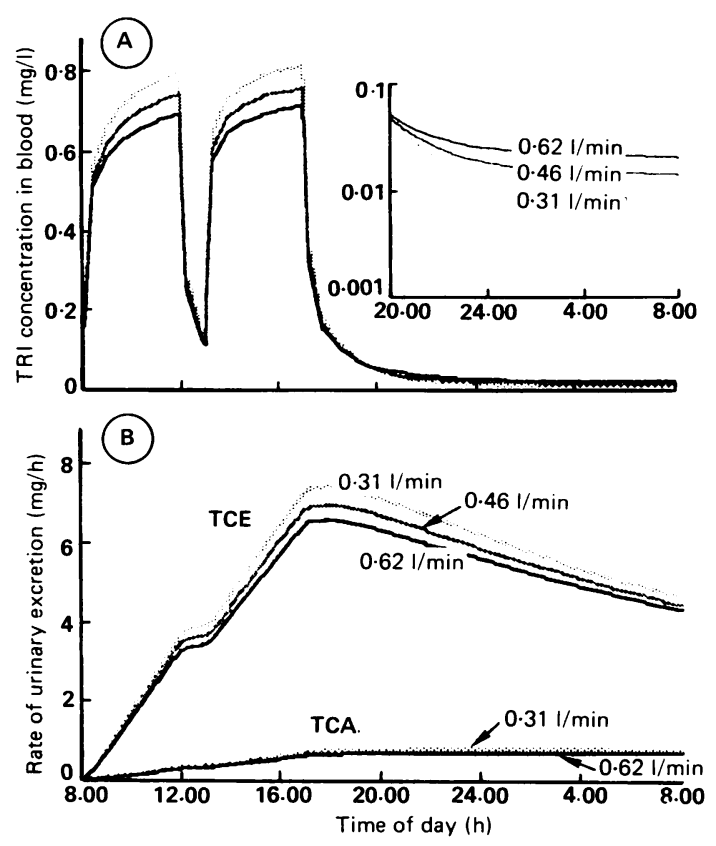

Figure 3 The influence of blood flow through fat tissue on the pharmacokinetic behaviour of TRI in obese men. $A$ $50 \mathrm{ppm} \times 8 \mathrm{~h}(8: 00-12: 00$ and 13:00-17:00 hours) exposure to TRI was simulated for three obese men (29.6 l fat tissue) with different blood flows to the tissue $(0 \cdot 31,0.46$, and $0.62 \mathrm{l} / \mathrm{min})$. Concentration of TRI in the blood is shown both on an arithmetic and a logarithmic scale (A) and the urinary excretion of TRI metabolites (TCA;TCE) as excretion rate (B).

volume of fat tissue $0.365 \mathrm{Bw}$ as opposed to $0.415 \mathrm{Bw}$ and $0.211 \mathrm{Bw}$ for male workers. The reason for choosing this value as the volume of the fat compartment in women was because according to Nagamine and Suzuki ${ }^{14}$ content of body fat in Japanese men was $11.5 \%$ of body weight, whereas that of women was $19.9 \%$. The fat content in a standard woman $(F)$ was thus calculated to match with that of a standard man $(0 \cdot 211 \mathrm{Bw})$ according to Davis and Mapleson ${ }^{10}$ by using the equation $F=0.211 \times(19.9 / 11.5)$. The blood perfusion through muscle or fat tissue was changed proportionally according to the change in volume of each tissue. The cardiac output of women was set at a level $10 \%$ less than that of men according to Guyton, ${ }^{12}$ and thus calculated from the formula $0 \cdot 266(\mathrm{Bw})^{0.7}$. The $\mathrm{Vmax}$ and $\mathrm{Km}$ were assumed to be sex independent, as there are no indications of sex related differences in drug metabolism in man. ${ }^{13}$ The urinary output of women was also assumed to be $10 \%$ less than that of men and is hence expressed by the formula $2.77 \times 10^{-5}(\mathrm{Bw})^{0.82}$.

A standard man $(70 \mathrm{~kg})$ and woman $(60 \mathrm{~kg})$ were submitted to a $50 \mathrm{ppm} \times 8$ hour trichloroethylene 

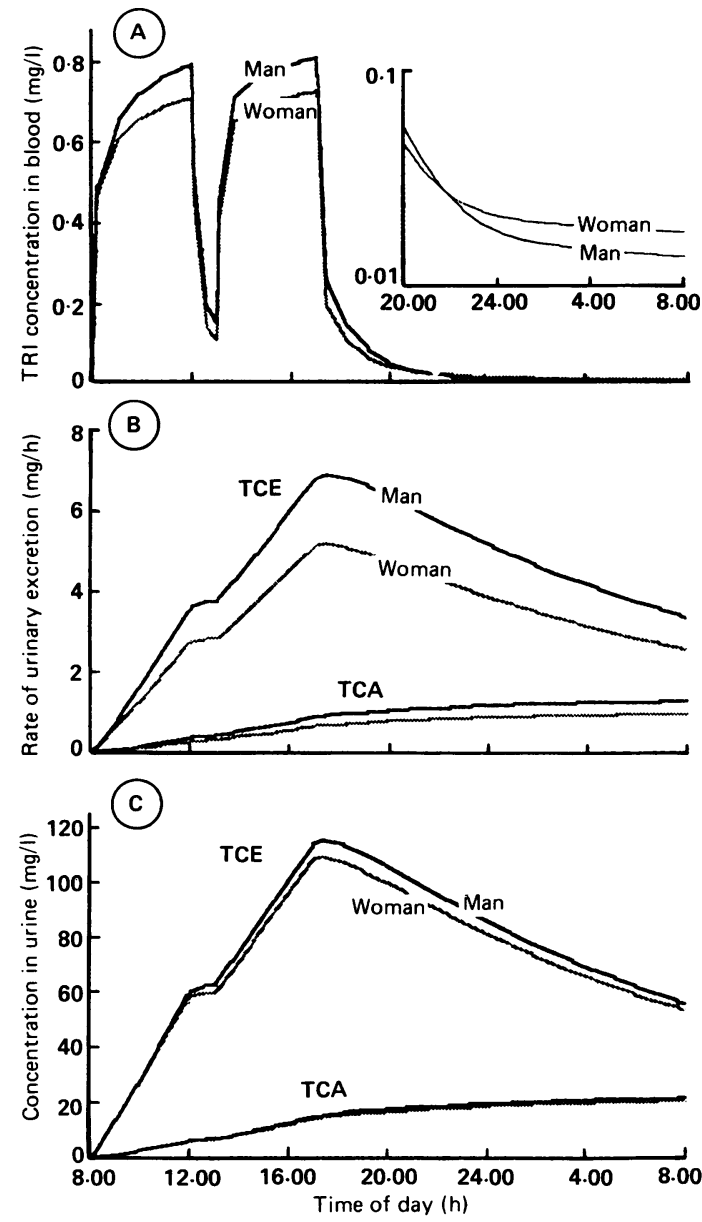

Figure 4 Sex difference in pharmacokinetic behaviour of TRI. Exposure to TRI at 50 ppm $\times 8 \mathrm{~h}(8: 00-12: 00$ and 13:00-17:00 hours) was simulated for a standard man $(70 \mathrm{~kg})$ and a standard woman $(60 \mathrm{~kg})$. The TRI concentration in blood is shown on both an arithmetic and a logarithmic scale (A) and the urinary excretion of TRI metabolites (TCA;TCE) in terms of excretion rate $B$ and urinary concentration (C).

exposure, and the concentration of trichloroethylene and the rate of excretion of urinary metabolites were computed over time (fig 4). The amount of trichloroethylene absorbed was smaller in the woman than in the man mainly because alveolar ventilation is lower in the woman. Also, the vapour absorbed in the female body was readily extracted into the ample mass of fat tissue. In consequence, during exposure, trichloroethylene concentration in the blood was lower in the woman than in the man (fig 4A). As the amount of trichloroethylene being released from fat tissue was larger, however, in the woman than in the man, the relation between man and woman was reversed in the course of time after exposure. The concentration of trichloroethylene in the woman calculated 16 hours after exposure was about $30 \%$ higher than that in the man.

In this simulation study, the specific activity of drug metabolising enzymes in the liver was assumed to be equal in both sexes. The female liver, however, is smaller in size than that of the man. Hence, the rate of overall trichloroethylene metabolism was accordingly lower in the woman. Together with the lesser amount absorbed, lesser amounts of metabolites were excreted in urine by the woman (fig 4B). The urinary metabolite concentration was also lower in the woman than in the man (fig 4C) although the difference was not so great as that seen in the rate of excretion. Agreeing with this simulation study, previous experimental studies ${ }^{1516}$ have shown that women retain trichloroethylene in the body in a lesser amount and excrete a lesser amount of metabolites in the urine than do men.

Knowledge of the toxicokinetics of chemicals is a basic requirement for understanding the relation between external and internal doses. Physiological factors such as sex and body build can alter this relation. Computer based physiological simulation models provide us with useful information particularly in this regard. The simulations presented in this report, however, are not intended as exac: predictions of the kinetic behaviour of trichloroethylene in industrial workers. Such predictions are of limited value as many of the conditions under which the simulations are made are only theoretical and do not reflect real exposure conditions. Our report should rather be regarded as an example of how such a model may be of value in elucidating some kinetic aspects of human exposure to organic solvent vapours.

Requests for reprints to: Dr Akio Sato, Department of Environmental Health, Medical University of Yamanashi, Tamaho, Yamanashi, 409-38 Japan.

1 Guberan E, Fernandez J. Control of industrial exposure to tetrachloroethylene by measuring alveolar concentrations: Theoretical approach using a mathematical model. $B r J$ Ind Med 1974;31:159-67.

2 Fiserova-Bergerova V, Vlach J, Cassady JC. Predictable "individual difference" in uptake and excretion of gases and lipid soluble vapours-simulation study. $\mathrm{Br} J$ Ind Med 1980;37:42-9.

3 Endoh K, Kaneko T, Sato A. A physiologically based pharmacokinetic model to describe the transfer of organic solvents in a human body - simulation of kinetic behaviour of trichloroethylene using a spread sheet program. Japanese Journal of Industrial Health 1989;31:335-41.

4 Fernandez JG, Droz PO, Humbert BE, Caperos JR. Trichloroethylene exposure. Simulation of uptake, excretion, and metabolism using a mathematical model. Br J Ind Med 1977;34:43-55.

5 Johanson G, Naslund PH. Spreadsheet programming-a new approach in physiologically based modelling of solvent toxicokinetics. Toxicol Lett 1988;41:115-27.

6 Ramsey JC, Andersen ME. A physiological model for the 
inhalation pharmacokinetics of inhaled styrene in rats and humans. Toxicol Appl Pharmacol 1984;73:159-75.

7 Koizumi A. Potential of physiologically based pharmacokinetics to amalgamate kinetic data of trichloroethylene and tetrachloroethylene obtained in rats and man. $\mathrm{Br} J$ Ind $\mathrm{Med}$ 1989;46:239-49.

8 Adolph EF. Quantitative relations in the physiological constitutions of mammals. Science 1949;109:579-85.

9 Sato A, Nakajima T, Fujiwara Y, Murayama N. A pharmacokinetic model to study the excretion of trichloroethylene and its metabolites after an inhalaton exposure. $\mathrm{Br} \mathrm{J}$ Ind $\mathrm{Med}$ 1977;34:56-63.

10 Davis NR, Mapleson WW. Structure and quantification of physiological model of the distribution of injected agents and inhaled anaesthetics. Br J Anaesth 1981;53:339-405.

11 Fiserova-Bergerova V, Vlach J, Singhal K. Simulation and prediction of uptake, distribution, and excretion of organic solvents. Br J Ind Med 1974;31:45-52.

12 Guyton AC. Basic human physiology: normal function and mechanisms of disease. 12th ed. Philadelphia, London, Toronto: Saunders, 1977:247.

13 Kato R. Sex-related differences in drug metabolism. Drug Metab Rev 1974;3:1-32.

14 Nagamine S, Suzuki S. Anthropometry and body composition of Japanese young men and women. Hum Biol 1964;36:8-15.

15 Nomiyama $K$, Nomiyama $H$. Metabolism of trichloroethylene in human. Sex difference in urinary excretion of trichloroacetic acid and trichloroethanol. Int Arch Arbeitsmed 1971;28:37-48.

16 Kimmerle G, Eben A. Metabolism, excretion and toxicology of trichloroethylene after inhalation. 2. Experimental human exposure. Arch Toxicol 1973;30:127-38.

Accepted 22 October 1990 